\title{
Assessing Long-term Impact of Values-based Community Health Education in Cambodia
}

\section{Amit Nirmal Cuttilan, Ravi Amran Cuttilanº, Si Min Chuac, Annelies Wilder- Smith $^{d}$}

\footnotetext{
${ }^{a}$ Medical Student, Yong Loo Lin School of Medicine, National University of Singapore

b Alumnus of Yong Loo Lin School of Medicine, National University of Singapore and Anesthesia Resident, Tan Tock Seng Hospital, Singapore

${ }^{c}$ Alumnus of Yong Loo Lin School of Medicine, National University of Singapore

d Professor of Infectious Diseases, Director, Global Health and Vaccinology Programme, Lee Kong Chian School of Medicine, Nanyang Technological University
}

\begin{abstract}
Introduction: Community Health Education (CHE) is a development strategy which aims to address the needs of communities in developing countries through an emphasis on moral values and civic education. The syllabus of the CHE program guides a trainer to find the needs of a developing community and take a moral values-based approach to health issues such as alcoholism, smoking, injuries to accidents, and sexually-transmitted illnesses. The fundamental philosophy is that of development as opposed to aid.
\end{abstract}

Methods: In November 2010 and February 2011, this training was conducted for leaders and volunteers from two Cambodian Non-Governmental Organisations (NGOs) involved in HIV prevention education and training in Cambodia. In order to investigate long-term impact, participants who underwent training sessions in November 2010 and February 2011 also underwent Focus Group Discussions (FGDs) and Key Informant Interviews (KIIs). Results: A total of 28 participants partook in the 3 FGDs and 5 participants took part in the KIls. Participants were able to recall a number of moral values and concepts from the training. These included forgiveness, love, altruism, unity, respect, empathy, teamwork, optimism, and hopefulness. The organisations were then able to use the CHE model to change the way their organisation worked together to achieve the goals in their communities. The participants were also able to use the teaching modalities employed by $\mathrm{CHE}$ sessions in their own work with their target communities.

Conclusion: The CHE training system has had a number of positive effects. They have influenced the personal lives of the participants, the way their organizations are run and the way they reach out to their target communities. In light of the themes identified in our results, we propose further research to 
compare the relative magnitude of all of these effects on these organizations in the long run compared to the short run.

Key Words: Community health worker, Cambodia, value-based education, community health education

\section{Introduction}

Community Health Education (CHE) is a development strategy which aims to address the needs of communities in developing countries through an emphasis on moral values and civic education. The syllabus of the CHE programme guides a trainer in finding the needs of a developing community and taking a moral values-based approach to health issues such as alcoholism, smoking, injuries due to accidents, and sexually-transmitted illnesses. ${ }^{1}$ The fundamental philosophy is that of development as opposed to aid.

The CHE strategy includes a large library of training materials to which trainers have access. A Training of Trainers 1 course (which is part of the CHE strategy) was conducted for leaders and workers from two Cambodian NonGovernmental Organisations (NGOs): Reproductive Health Association of Cambodia (RHAC) and Trans-World Radio (TWR). Both NGOs are involved in HIV prevention education and training in Cambodia. The course included the fundamental approach of finding the health needs of a developing community as well as the values-based approach of meeting those needs. The initial training of NGO workers was conducted by a team of trainers from Singapore. These NGOs subsequently applied the CHE strategy to their work with communities in Cambodia.

This study aims to determine what effect the moral value-based training had on the personal attitudes and practices of participants from the NGOs, and whether this training resulted in any changes in the structural set-up of the NGO and programmatic approaches. This was done through Focus Group Discussions (FGDs) and Key Informant Interviews (KIIs) in June 2013.

All components of this study were approved from the National University of Singapore Institution Review Board prior to the commencement of this project.

\section{Methods}

\section{Organisations}

RHAC is an NGO which works on issues relating to reproductive health. It is a large nonprofit organisation funded mainly by United States Agency for International Development (USAID), among other donors. Their work in the community is done by CHE volunteers and health centre staff who deal with mother and child health, sexually-transmitted infections, vulnerable groups, and youth health.

TWR is a faith-based NGO whose main ministry is faith-based radio broadcasts. In addition to the broadcasts, they also make visits to communities of their listeners to organize rallies and engage in community development projects, which they term "holistic ministry." They are a small organisation with a full time staff of 12. They use CHE principles as part of their community development strategy.

The training conducted in these organisations included the CHE approach of focusing on helping the community through the facilitation of development rather than provision of relief. This enables sustainable development of the community. The training also included specific values-based strategies to improve the health of the communities. The strategies for improving reproductive health were more

July 2018. Christian Journal for Global Health 5(1):21-32 
actively promulgated by RHAC as it was their organizational focus.

\section{$A B C$ and SAVE Education}

We based the health education portion of our trainings on the ABC and SAVE approaches to HIV/AIDS prevention as well as values-based approaches. The ABC approach to sexual health and prevention of HIV/AIDS was first used in 1992. This approach based HIV prevention on three interventions; abstinence, being faithful as well as correct, and consistent condom use. This approach was credited with the reduction of HIV/AIDS rates in Uganda from about $15 \%$ in the early 1990 s to about $5 \%$ by $2001 .^{2}$

In 2003, the African Network of Religious Leaders living with HIV and AIDS coined a new prevention approach with the acronym "SAVE" (Safer practices, Available medication, Voluntary counseling and testing, Empowerment) intended to encompass a far wider range of prevention needs. ${ }^{2}$

\section{Values-based Education}

Much of the research on reproductive health intervention focuses on knowledge-based "sex education," rather than values-based education. ${ }^{3}$ On the other hand, while educationbased HIV/AIDS prevention has been gaining traction over the past years, this should be distinguished from the values-based approach. The education approach is based on raising awareness of HIV/AIDS, while the values-based approach is focused on moral and civic education that involves many aspects of life, including sexual practices.

While there has been some research regarding the criticism, perspectives of, and challenges associated with a values-based education approach, literature regarding the effectiveness of such an approach is relatively lacking. $4,5,6,7$

\section{Interviews}

In order to investigate long-term impact, participants from RHAC and TWR who underwent training sessions in November 2010 and February 2011 were invited to attend FGDs. In addition, KIIs were conducted with the leaders of RHAC and TWR. These interviews and discussions were carried out in the offices of RHAC and TWR. All KIIs and FGDs were conducted in each organization's national headquarters in Phnom Penh, Cambodia, between the sixth and ninth of June, 2013.

In order to maximise representation of views, all participants of the training courses were invited for the focus group interviews. From RHAC, there were a total of 22 participants out of 60 that were invited. These participants were involved in FGDs 1 and 2 . From TWR, there were a total of 6 participants out of 12 that were invited. These participants were involved in FGD 3. The main reason for certain invited participants' inability to participate in the FGDs was that they were posted to the provinces for field work and were unable to be at the Phnom Penh headquarters of the NGOs at the time the discussions were carried out.

KIIs were conducted with the heads of the NGOs to investigate the impact the training had on the organisational structure and practices. Three of these were done with leaders of TWR and two with leaders of RHAC. KII interviewees from TWR had conducted training sessions, while those from RHAC had only participated as trainees. All FGD participants had also only participated as trainees.

The interviews and focus group discussions were conducted using a semistructured interview guide. The researcher had a prepared set of questions, which were constructed in line with the aims of the study. During the sessions themselves, however, participants were encouraged to elaborate on points brought up even if they were not immediately relevant to the questions under discussion. All KIIs were conducted in English, while for the FGDs, participants who spoke both 
English and Khmer translated for those who could only speak Khmer.

\section{Results}

The key takeaways from the participants can be separated into the impact on the participants, the impact on the organizations as well as the impact on the community.

\section{Personal impact}

The most important moral value which was brought up during every FGD and KII was that of forgiveness. Participants were able to recall a number of other moral values and concepts from the training. These included love, altruism, unity, respect, empathy, teamwork, optimism, and hopefulness. They also mentioned a change in opinion over the course of the training, especially regarding the values of honesty, respect, and forgiveness. The training also highlighted the importance of sharing experiences with one another.

However, they found some values, such as altruism, difficult to implement. For example, altruism was difficult to teach as the participants felt that it was not part of their culture to help people without expecting anything in return.

\section{Impact on organisations and the community}

The NGOs used the CHE model to improve on their work processes by applying moral values to their daily practices. They were then able to design projects to cater better to the needs of the communities they served.

Apart from moral values, the communities they served learned to take ownership of the trainings by planning locations for the trainings, and by taking ownership of the problems they faced in the community. This can be closely tied with the teaching of development and relief. The participants gained from learning about the differences between development and relief, and how the latter would help them progress as a community. The role plays helped participants from the communities learn about the importance of relief in the short-term and development in the long-term, where they would continue developing their communities once outside help had left.

\section{Areas for improvement}

Discussion on areas for improvement revealed four overarching themes: implementation skills, including authorities in training, avoiding Christian anecdotes, and facilitation of learning. Many participants mentioned they would like the training to further include counseling and facilitation skills in addition to moral values training. One participant also mentioned including one lesson regarding the community, with regard to how to develop their community to be prosperous. One participant felt that village and commune authorities should be invited to the training as training them could help change the way decisions are made in the community.

Although all felt that the training was appropriate to the Cambodian context, the Christian references during role plays could pose as a challenge to sharing the concepts with nonChristians of the community. Some participants felt that the principles being taught to them were exclusively for Christians and hence did not think they were applicable to them. A few participants also felt that facilitation of learning could be improved by providing handouts at the start of the training instead of the end so they could take notes. One also suggested that participants be renumerated for their time and transport expenses.

\section{Hopes and dreams}

When asked about their hopes and dreams, the replies were varied, and included having better living standards such as clean water and electricity, and having more roads and modern facilities in their villages; building their own businesses and owning a car and villa; having their family avoid vices such as smoking, 
alcohol, and gambling; and living in peace and harmony.

\section{Discussion}

\section{Personal Impact}

Moral values were a key takeaway for participants from the trainings. The value of forgiveness came up in almost every KII and FGD. Not only were participants able to see a personal change in their lives, they were also able to apply forgiveness in their family lives. However, it was noted that this concept was not initially easy to bring across in Khmer as there was no direct Khmer translation for it. Closely tied to the theme of forgiveness were patience and anger management. The participants also learned how to modify their behavior through meditation: one participant shared how moral values were imperative in helping to defuse tense situations that arose in their organisation.

In a country where the Khmer Rouge regime had caused much hardship and hatred among its people, participants found the practice of meditation to be helpful with issues of forgiveness and anger management. While only a few training sessions included a meditation session, those who took part in it gained from it personally, and were able to help their organisations as well. This was a positive step in helping them to build good relationships within their organisations.

Another value that came up during KII's was a holistic understanding of health, through one of the lessons titled "good body, good health." There was a change in the mindsets of the participants about what health was; they were no longer solely focused on physical well-being but also their emotional well-being. This principle of a holistic understanding of health, coupled with the lessons on forgiveness, patience, and anger management, also helped the participants to improve on their relationships with both their family members as well as their colleagues.

The lesson about the tree of hope and tree of despair was well remembered by the interviewees, and they used them to train the community leaders as well as their own subordinates. They wanted to apply these lessons in a broader scale in the community.

Altruism was another key concept taught during the training sessions, focusing on the topic of unconditional giving. Most volunteers in the organisations did not get any remuneration other than money for transport, however most of them were willing to do volunteer work because of the potential they saw in their beneficiaries passing on this knowledge to the community. Some participants not only shared the lessons learned with others, they also requested for materials to pass them on to family and friends.

It was agreed that many of the moral value lessons were appropriate to the Cambodian context because they were applicable and not so different from the Buddhist beliefs of compassion and doing good. They felt that these would be relevant in development especially at the provincial levels.

The certificate given to participants at the end of the training session seemed, by itself, to be a motivator for participants to behave in a certain way, as they felt empowered to apply the concepts learnt.

\section{Impact on organizations}

The NGOs' operations were also influenced by the CHE model. Different stakeholders were better able to work together when they had a single, shared goal in mind. The principles in CHE were seen to complement the ways that the organisations were being run originally. For TWR, it provided them with a framework for engaging in holistic ministry, and seeing to the physical needs of the communities they were working with. TWR was not only able to apply moral values into their organisation, but they were also able to introduce them to their 
listeners during rallies. Once again, role plays were impactful as they were attractive and kept people engaged. The CHE curriculum provided a model for them to offer concrete help to their listeners; both in terms of improving the communities and spreading basic healthcare knowledge. They also used some of the methods taught by the CHE curriculum such as role plays and root cause analysis. They felt that this made a greater impact on the communities than previous attempts such as distributing food.

For RHAC, the CHE principles complemented the unity and compassion that had been part of the organisation's shared values. They used a model of supportive supervision to instill moral values among team members, encourage teamwork among members of the organisation and value each member's contributions. Working in teams helped in sharing knowledge among team members, and each of them was able to share responsibilities in solving the problems together. RHAC had developed a set of ten shared values as a company and the CHE training helped reinforce them. Within RHAC, different leaders had different ways of applying CHE principles with their teams. For example, leaders in the IT team fostered teamwork by bringing up difficult problems for discussion so that a solution could be found while working together. These aspects of organisational performance were not directly and totally attributable to the influence of CHE training. However the participants did feel that the CHE principles reinforced these good practices.

RHAC also found that the moral values training had improved the Quality of Care (QOC) score that was a performance indicator assessed by an external group. They have linked moral values lessons to sexual and reproductive health as well as community development education in the community. But perhaps the most telling example of how CHE has had an impact on RHAC was the following account of how a new project was being approached. They designed projects to cater both to the needs of the community as well as suit the skills of their stakeholders who run the projects.

\section{Impact on the Community}

In addition to the moral values recalled, participants remembered some of the teaching modalities used in the CHE sessions very well. The one that stood out the most was the role playing, which some said they began to apply in their own organizations as it helped keep participants engaged in the sharings. They found that this method was very applicable to the local context, enabling concepts to be shared in a way that was received easily, whether it was the NGO's staff (who had a higher educational background) or the community leaders (who may not have had any formal education). Role plays also proved to be flexible teaching tools, as they could be adapted to the needs of a particular community or group of learners. The role plays were especially effective for participants who were illiterate as ideas could be communicated easier through role plays than through normal lessons. Role plays did have their limitations in some contexts though, as villagers were not always willing to participate in them.

The adaptability of the CHE lessons was a strength that was identified. TWR, for instance, planned two to three lessons based on CHE principles whenever they went to the field to train villagers. They would apply the most relevant lesson to the participants, targetting the needs they saw in the community. This flexibility also made it incumbent on the facilitators to be flexible and adapt the topics to relate to the real context of the target groups.

The trees of hope and despair were also a useful training tool for the participants from the villages. It helped participants to understand their situations better, contextualise their problems, and understand the importance of applying moral values in their lives. Participants 
were able to identify the issues they faced in their communities, think of the pros and cons of the issues, and then were taught lessons on how to respond to these issues. For example, the villages in the Puok district came up with a list of problems in their community of which alcohol was the most prevalent, and then they were able to focus more on how to deal with alcoholism.

There was also an element of taking ownership of the trainings among the members of the community. Participants took an active role in helping to set up locations for training sessions, instead of relying on members of the various organisations to set them up for them. They also started to take ownership of their own problems, first by acknowledging the problems they had in their community; the trees of hope and despair helped the villagers to understand that having good moral values would benefit them in the long run. Through this, they learnt how to analyse, find the root cause, and eradicate the problem. For example, some villages had a problem with gangsterism among the youth in the communities, as they used to disrupt moral values training sessions; however, after dealing with the root cause of gangsterism, many of the youth started changing and helping out in the community rather than disrupting day-to-day activities.

However, this sense of ownership took a while to get instilled in the community. One TWR interviewee noted that they spent a couple of years trying and helping the community understand that the problem (alcoholism) was not an outsider's problem, but a problem within the community itself.

The CHE curriculum had the effect of empowering communities to solve their own problems and reduce their reliance on relief from outsiders, as well as show the NGOs the importance of a partnership with the community. TWR saw that CHE led to change from the "inside out" rather than forcing people to change against their will. Anecdotes of changes they had seen in their work with the community included facilitating smoking cessation, making people confident to seek help for HIV infection as well as increased standards of health and hygiene.

The focus on enabling the community to allocate its resources to meet its own needs, by giving them tools to analyse their problems and resources, rather than providing money or resources for them, has empowered them and led to a positive ripple effect in the community.

\section{Challenges Faced and Areas for Improvement}

Interviewees identified a number of challenges posed by the situation in Cambodia. One was the priorities of some rural villagers in the way they spent their money - they tended to spend on things such as mobile phones, alcohol, and cigarettes. In other communities, the problem was gambling. Some participants suggested that time spent gambling led to rubbish being seen everywhere in the village.

There were also instances where villagers did not open up and participate in the training sessions, but the NGO found that this improved over multiple visits as rapport was built between the NGO and villagers. Once the trainers were able to get the participants to sit through a Training of Trainers (TOT), it was easier to pass on their knowledge to them.

Another challenge was how people had a "relief" mindset. This led people to expect some form of payment, such as a per diem fee for attending training. This mindset also made it difficult for NGOs to retain employees that they trained. In TWR, they recruited employees for competencies in personality and commitment, and trained them; however, they then lost them to other NGOs that are able to pay them more. RHAC too was unable to maintain their volunteer pool of 22,000 volunteers as they were not able to remunerate them for their work. Whenever another organisation was able to offer them even a minimal amount of money, it was a 
very attractive proposition. So it was hard for them to build up a culture of volunteerism when other NGOs offered money for similar jobs.

Another challenge that both RHAC and TWR faced was that NGOs, in general, were reluctant to work with each other. This was particularly apparent when faith-based organisations were involved. They had a resistance to networking, saying, "This is my territory, I won't cross into yours, don't you cross into mine!" Moreover, working with a secular organisation like RHAC did not bode well with one of the other organisations. There was one project where RHAC was working with two faith-based organisations. One felt very strongly that they did not want to work with a secular organisation while the other was very hesitant until they found out that the project was based on building relationships.

At times the CHE training was only effective after a period of time, requiring repeat trainings from multiple visits to show the communities that the problems they were being taught about were within the community itself. For example, TWR noted that communities in the process of development needed time for more training.

A challenge that echoed through a number of interviews was the lack of resources, both financial and manpower limitations, that made it difficult for them to expand their work to other target groups. If more resources were available for the organisations, an area for improvement for the CHE framework would have been to focus different trainings for different groups of people.

The trainers felt that the CHE strategy was easy to implement after going through TOT1; however, it was not as easy to get participants to sit through the entire training session. They also felt that supplementary moral values trainings were useful, so that they were able to understand and apply moral values in their lives and also in subsequent training sessions. The trainers also acknowledged that four days for a TOT session was ideal, while the five-day-long sessions seemed to drag on. During one of the focus group discussions, the participants also wanted another TOT session, as they felt that they wanted to refresh and upgrade their skills further. Those who did attend more than one session felt that the second session served to reinforce what they had learnt before.

While many of the lessons were suitable to the Cambodian context, there were some points that were not apt for the context of each community and conflicted with the local values. For example, the adapted parable of the Good Samaritan, where a monk passing by chose to not help the victim, was not received well by participants. The language barrier was also an issue as some Khmer translations did not make sense to participants. The need for translation also led to the lessons taking longer to cover. In villages, there was also the problem of literacy as group work involved presenting on large pieces of paper. Sometimes villagers were partnered in groups where none of them were literate. In these cases, they did not seem as interested in those segments of the training session.

\section{Hope for the Future}

At the end of the KII or FGD, participants were invited to share their hopes for the future and how the training programme could help achieve them. Some participants felt that the training should have been extended to other members of RHAC staff beyond just the leadership and middle management. Others wanted it to be spread beyond RHAC; some even went so far as to suggest that certain components of the CHE training, particularly the moral values, should be incorporated into the public school curriculum.

Other staff from RHAC spoke about seeing improvements in the work they were doing, such 
as seeing reduced maternal deaths, greater utilisation of public health centres, reduced family violence, and less discrimination against people who are infected with HIV/AIDS, particularly vulnerable groups.

For the organisation, there were hopes for better working relationships between colleagues in order to improve the services, greater empathy for clients, as well as greater accountability and transparency within the organisation.

Others hoped for a better quality of life, both in terms of reduced stress in the workplace and better relationships with their families. They also hoped that the moral value lessons would help them to reflect more about how they acted and hence help them to change their behavior.

One of the TWR interviewees felt that integrating media into CHE could help disseminate the strategies better than merely using training sessions. CHE has been used in Cambodia for over 20 years, and TWR has the capacity to reach out to many more people using their radio broadcasts. While normal lessons are limited to a small number of individuals, media broadcasts of CHE lessons could reach out to much more people whilst still not using too much of the limited resources that the organisation has.

A volunteer from RHAC also agreed that using media could help them reach out to more people, making more efficient use of their volunteers. However, one problem with using media would be trying to contextualise it for the different target audiences in the different parts of Cambodia, as a CD or a radio broadcast would not be able to focus on topics which fit with the context of different villages across the country.

Some felt that the way to achieve this was through changing peoples' perceptions, which would change their thinking, which in turn would lead to a change in behavior. This tied in with the hope that future generations would be able to live better lives than the participants did.

Another RHAC member reflected that moral values would be more useful if they were integrated in every program that RHAC did. Instead of just having stand-alone moral value trainings in the community, integrating it into teachings that focus on agriculture or health would better help to pass on the values. Finally, one hoped that there would be a tool to monitor the progress of moral values and the impact of this training.

\section{Limitations}

Participants reported remembering only a few of the moral values that they had been taught over the course of the training program, admitting that there were likely a number of aspects of the content they had forgotten. This did, however, enable us to see which topics and values they found useful or applicable in their lives or organisations. Participants reported that the values they remembered at the time of the interview (which for many was about two to three years after they had attended the training session) were those that they found useful and had been implementing, either in their personal lives or in their organisations. One recounted, "I do not remember all the subjects that I have learned from the training but I thought maybe I lack something that I didn't apply in my life. If I look at the lesson maybe I will remember."

There is also a possibility of interviewer bias with participants having a tendency to report positive aspects of the CHE programme and its effects more than negative ones.

There is also a probability of responder bias due to the FGDs being conducted in English with participants (who were proficient in English) acting as interpreters for fellow participants who answered in Khmer.

The impact of the training on the community is only assessed indirectly in this study, as it depends on the responses of the NGO workers during the FGDs and the NGO leaders during KIIs. This impact is inferred by the interviewer based on the responses of the FGD 
and KII participants, and as such, the observations are limited to these perspectives only.

It is possible that some relevant themes would not have been captured because of the participants who were invited but unable to participate in the FGDs.

It is possible that some of the points brought up were "lost in translation." Great efforts were made during the sessions, however, to clarify what was said, through repetition and asking for concrete examples of abstract ideas.

The organisations of RHAC and TWR had trainings other than those with CHE principles, and there could have been an overlap in material between these. As such, it is likely that some participants attribute to CHE impact from other training as well, especially where there is an overlap.

Being a qualitative study, the aim is to find the spectrum of responses in the population being studied and not the prevalence of each individual response. As such, we are unable to draw firm conclusions on the importance of each theme elicited from the FGDs and KIIs. However, the qualitative study has its strengths as well; it helped us elicit details on behaviour and personality characteristics that a quantitative study would not be able to match. This study helped us to learn more about how applicable CHE was in the Cambodian setting based on the responses of the trainees to the training as well as their application of these lessons in their target communities.

\section{Conclusion}

From the findings, it is clear that the CHE training system had a number of positive effects. They have influenced the personal lives of the participants by helping them recall moral values and concepts from the trainings. These not only helped in their personal lives but some of them were able to pass on this knowledge to others using the handbooks they received from the training sessions. These personal values also aided participants in improving their organisations' internal operations as well as how the organisations engaged the community. Both of the organisations started using CHE principles in the way they solved their problems, working in more holistic ways to solve problems. They also employed methods used in the CHE workshops in their work with the communities. This helped with their education efforts in their respective target communities. The two organisations sampled had a number of differences. While both of them were NGOs, RHAC was a secular organisation whereas TWR was faith based. However, both were able to see the benefits of the CHE training, both in the short and long term. In light of the themes identified, we propose further research to compare the relative magnitude of all of these effects on these organisations in the long run compared to the short run.

\section{References}

1. Global Community Health Evangelism Network. [Internet] What is CHE. [Cited 2013

September 20]. Available from: https://www.chenetwork.org/what.php

2. Jones H, Chalcraft K. [Internet\} SAVE : A comprehensive approach to HIV prevention, care \& support. 2009. [Cited 2013 March 20]. Available from: http://www.ealliance.ch/en/s/resources/library/detailview/doc ument/22662/view/single/

3. Hull TH, Hasmi E, Widyantoro N . "Peer" educator initiatives for adolescent reproductive health projects in Indonesia. Reproductive Health Matters 2004; 12(23):29-39. https://doi.org/10.1016/S0968-8080(04)23120$\underline{2}$

4. Akar B. Teaching for citizenship in Lebanon: Teachers talk about the civics classroom. Teaching and Teacher Education. 2012; 28(3):470-480. https://doi.org/10.1016/j.tate.2011.12.002 
5. Tan C. Two views of education: Promoting civic and moral values in Cambodia schools. International Journal of Educational Development. 2008; 28(5): 560-570. https://doi.org/10.1016/j.ijedudev.2007.07.004

6. Willemse M, Lunenberg M, Korthagen K. Values in education: a challenge for teacher educators. Teaching and Teacher Education. 2005; 21(2):205-217. https://doi.org/10.1016/j.tate.2004.12.009

7. Godia PM, Olenja JM, Lavussa JA, Quinney D, Hofman JJ, van den Broek N. Sexual reproductive health service provision to young people in Kenya; health service providers' experiences. BMC Health Services Research. 2013; 13: 476. https://doi.org/10.1186/14726963-13-476

Peer Reviewed: Submitted 11 Dec 2015, Accepted 24 May 2018, Published 12 July 2018

Competing Interests: None declared.

Correspondence: Amit Nirmal Cuttilan, Yong Loo Lin School of Medicine, National University of Singapore, Singapore. amithnc@gmail.com

Cite this article as: Cuttilan A N, Cuttilan R A, Chua S M, Wilder-Smith A. Assessing long-term impact of values-based community health education in Cambodia. Christian Journal for Global Health. July 2018; 5(2):21-31. https://doi.org/10.15566/cjgh.v5i1.100

(C) Cuttilan A N, Cuttilan R A, Chua S M, Wilder-Smith A. This is an open-access article distributed under the terms of the Creative Commons Attribution License, which permits unrestricted use, distribution, and reproduction in any medium, provided the original author and source are properly cited. To view a copy of the license, visit http://creativecommons.org/licenses/by/4.0/

$$
\text { www.cjgh.org }
$$

July 2018. Christian Journal for Global Health 5(1):21-32 